\title{
Protein energy malnutrition increases arginase activity in monocytes and macrophages
}

\author{
Karina Corware ${ }^{1}$, Vanessa Yardley ${ }^{2}$, Christopher Mack ${ }^{1}$, Steffen Schuster ${ }^{3}$, Hafid Al-Hassi', Shanthi Herath ${ }^{4}$, \\ Philip Bergin ${ }^{5}$, Manuel Modolell ${ }^{6}$, Markus Munder ${ }^{7}$, Ingrid Müller ${ }^{1}$ and Pascale Kropf ${ }^{{ }^{*}}$
}

\begin{abstract}
Background: Protein energy malnutrition is commonly associated with immune dysfunctions and is a major factor in susceptibility to infectious diseases.

Methods: In this study, we evaluated the impact of protein energy malnutrition on the capacity of monocytes and macrophages to upregulate arginase, an enzyme associated with immunosuppression and increased pathogen replication.

Results: Our results show that monocytes and macrophages are significantly increased in the bone marrow and blood of mice fed on a protein low diet. No alteration in the capacity of bone marrow derived macrophages isolated from malnourished mice to phagocytose particles, to produce the microbicidal molecule nitric oxide and to kill intracellular Leishmania parasites was detected. However, macrophages and monocytes from malnourished mice express significantly more arginase both in vitro and in vivo. Using an experimental model of visceral leishmaniasis, we show that following protein energy malnutrition, the increased parasite burden measured in the spleen of these mice coincided with increased arginase activity and that macrophages provide a more permissive environment for parasite growth.
\end{abstract}

Conclusions: Taken together, these results identify a novel mechanism in protein energy malnutrition that might contributes to increased susceptibility to infectious diseases by upregulating arginase activity in myeloid cells.

Keywords: Arginase, Macrophages, Monocytes, Nitric oxide, Leishmaniasis

\section{Background}

Undernutrition results from insufficient dietary intake, poor absorption and/or inadequate use of the nutrients consumed. It is a major health concern, mainly throughout the developing world and children are especially affected. An estimated 826 million people in the world are undernourished, of those $95.9 \%$ are in the developing world [1]; 178 million children under the age of 5 are stunted and 55 million are wasted [2]. In 2011, 6.9 million children under 5 years died, one third of these deaths were related to increased susceptibility to infections due to undernutrition [2]. Protein energy malnutrition (PEM) is thought to be one of the major causes of immunodeficiency. PEM and infection have always

\footnotetext{
* Correspondence: p.kropf@imperial.ac.uk

${ }^{1}$ Department of Medicine, Section of Immunology, Faculty of Medicine, Imperial College London, Norfolk Place, London W2 1PG, UK

Full list of author information is available at the end of the article
}

been closely associated, as PEM is a common cause of susceptibility to infections. Undernutrition in children negatively impacts on thymic development, therefore compromising immune responses [3]. In malnourished patients, both innate and acquired immunity are affected $[4,5]$ and common immune defects are an imbalance in the ratio of $\mathrm{CD} 4 / \mathrm{CD}^{+} \mathrm{T}$ cells [6], low expression levels of CD69 on lymphocytes [7], biased T helper cell responses [8], reduced antibody responses [6]; impaired phagocytosis by macrophages $[9,10]$, lower nitrite/nitrate concentrations in wound fluid [11] and decreased NF-kappaB activation by macrophages [12] have also been shown in experimental models of PEM.

Arginase, an enzyme that catalyses the conversion of L-arginine, can be upregulated in murine macrophages, dendritic cells and neutrophils [13], however, human 
neutrophils constitutively express arginase (reviewed in [13]). There are two isoforms of arginase in mammals, arginase I and arginase II [14,15]. The catabolism of L-arginine by arginase can regulate the availability of $\mathrm{L}$-arginine and therefore the efficiency of T cell responses: increased catabolism of L-arginine by arginase results in the depletion of L-arginine from the microenvironment; since L-arginine is essential for efficient $\mathrm{T}$ cell activation, this decrease in L-arginine results in impaired $\mathrm{T}$ cell responses [13,16-18]. In addition, the catabolism of L-arginine by arginase results in the production of ornithine, which is further catabolised into polyamines that are crucial for cell division; and into proline, which is the building block for collagen synthesis. L-arginine is also the substrate for nitric oxide synthase (NOS), that catabolises L-arginine into nitric oxide (NO), a molecule critical for the regulation of vascular homeostasis, neurotransmission and the killing of many pathogens [19]. Therefore, by competing for the shared substrate L-arginine, increased arginase activity also modulates the production of NO. Consequently, deficiencies in L-arginine metabolism can disrupt many cellular and organ functions.

Increased arginase activity is common to several pathological and physiological conditions: it has been prominently described in cancer $[16,18]$, but also in asthma, myocardial infarction, pregnancy and infectious and autoimmune diseases (summarised in [13]). We have recently shown that increased arginase activity is a marker of disease severity in HIV seropositive (HIV+) patients [20], in patients with visceral leishmaniasis and HIV co-infection [21] and in patients with visceral [22] and cutaneous [23] leishmaniasis. Malnutrition is a major contributor to both progression and severity of visceral leishmaniasis (VL) and several studies in the mouse have shown that PEM and micronutrient deficient diet exacerbates VL [24].

Nutrition has been shown to impact on the phenotype of macrophages: in obesity, adipose tissue is characterized by infiltration of inflammatory macrophages, in contrast to lean adipose tissue, where a majority of anti-inflammatory macrophages are present [25]. In the present study, we tested the hypothesis that malnutrition impacts on macrophage effector functions and results in increased arginase activity, therefore contributing to increased susceptibility to disease.

\section{Methods}

Mice

Specific pathogen free female BALB/c mice (18 g) were purchased from Charles River (UK) and were kept in individually vented cages. The animal colonies were screened regularly for mouse pathogens and consistently tested negative.

\section{Ethics statement}

Animal experiments were performed in accordance with home office and institutional guidelines. The project licence (PPL 70/6712) was approved by the Imperial College Central Animal Welfare \& review Body (AWERB) committee.

Mice were fed on the different diets following a 3-day period of acclimatisation. Control mice were fed a diet consisting of $14.4 \%$ protein, $61.7 \%$ carbohydrates and $2.7 \%$ fat (RM1, Harlem Laboratories Inc, Madison, Additional file 1). The group of mice that was malnourished (MN group) was fed a diet consisting of $0.7 \%$ protein, $87.0 \%$ carbohydrates and $4.1 \%$ fat (Modification of TestDiet AIN-93 M w/No protein, TestDiet, Additional file 2). Both diets had similar amounts of calories: control group $=3.5 \mathrm{kcal} / \mathrm{g}$ and $\mathrm{MN}$ group: $3.85 \mathrm{kcal} / \mathrm{g}$ and both groups of mice had ad libitum access to food and water.

\section{Sample collection}

Bone marrow cells were obtained by flushing the femurs of BALB/c mice and precursor cells were used immediately for flow cytometry or were frozen in PBS containing $1 \%$ protease inhibitor cocktail (Sigma) for the determination of arginase activity. To obtain bone marrow derived macrophages (BMMФ), fresh precursor cells were cultured for 8 days in a humid atmosphere at $37^{\circ} \mathrm{C}$ and $10 \% \mathrm{CO}_{2}$ in hydrophobic Teflon bags in DMEM (Sigma) containing 10\% heat-inactivated FCS (Gibco), 5\% horse serum (Gibco), the supernatant of L929 fibroblasts at a final concentration of $15 \%(\mathrm{v} / \mathrm{v})$ as a source of colony stimulating factor (CSF), $50 \mathrm{IU} / \mathrm{ml}$ penicillin, $50 \mu \mathrm{g} / \mathrm{ml}$ streptomycin, and $292 \mu \mathrm{g} / \mathrm{ml} \mathrm{L-glutamine} \mathrm{(Sigma)} \mathrm{as}$ described in [26]. To obtain bone marrow-derived neutrophils, fresh precursor cells were cultured for 7 days as described in [27].

Peripheral blood mononuclear cells (PBMCs): blood was collected in EDTA tubes by cardiac puncture and PBMCs were isolated by density gradient centrifugation on Histopaque-1077 (Sigma). Before harvesting the interphase, the plasma was collected and frozen for further analysis. Cells were washed in phosphate buffered saline (PBS) and were used immediately for flow cytometry or were frozen in PBS containing $1 \%$ protease inhibitor cocktail (Sigma) for the determination of arginase activity.

Spleen cells: spleens from BALB/c mice were homogenised in PBS and red cells were lysed with red cell lysis buffer as described in [27] and were frozen in PBS containing $1 \%$ protease inhibitor cocktail (Sigma) for the determination of arginase activity.

\section{Macrophage activation}

Mature BMMФ and mature BM-derived neutrophils were harvested and $5 \times 10^{5} \mathrm{BMM} \Phi / \mathrm{ml}$ were plated in 
DMEM (Sigma) containing 5\% heat-inactivated FCS (Gibco), $50 \mathrm{IU} / \mathrm{ml}$ penicillin, $50 \mu \mathrm{g} / \mathrm{ml}$ streptomycin, and $292 \mu \mathrm{g} / \mathrm{ml} \mathrm{L-glutamine} \mathrm{(Sigma)} \mathrm{and} 5 \times 10^{-5} \mathrm{M} \mathrm{2-}$ mercaptoethanol (Sigma). BMMФ were stimulated with $20 \mathrm{U} / \mathrm{ml} \mathrm{IL}-4$ or with $100 \mathrm{U} / \mathrm{ml} \mathrm{IFN}-\gamma$ and $500 \mathrm{U} / \mathrm{ml} \mathrm{TNF}-\alpha$ (Peprotech) or with $1 \mu \mathrm{g}$ LPS (Sigma) for 72 hours, unstimulated macrophages were used as control. Mature BM-derived neutrophils were stimulated with $20 \mathrm{U} / \mathrm{ml}$ IL-4 (Peprotech) and unstimulated mature BM-derived neutrophils were used as control.

\section{Phagocytosis assay}

Mature BMMФ $\left(1 \times 10^{5}\right.$ BMM $\left.\Phi\right)$ were incubated for 1 hour with pHrodo $^{\mathrm{mm}}$ Bioparticles $^{\circ}$ fluorescent particles according to the manufacturer's protocol (Molecular Probes). Analysis of the mean fluorescence intensities (MFI) was performed on a LSRII (BD Bioscience) and results were analyzed using Summit v4.3 software.

\section{Flow cytometry}

Antibodies used were as follows: anti-Ly-6C (clone HK1.4, eBioscience), anti-Ly-6G (clone RB6-8C5, eBioscience), anti-F4/80 (clone BM8, BD Biosciences), anti-arginase I (Polyclonal sheep IgG, R\&D). Cells were washed with PBS, the fixation step was performed with $2 \%$ formaldehyde in PBS and the permeabilisation step with $0.5 \%$ saponin in PBS. Analysis was performed on a LSRII (BD Bioscience) and results were analyzed using Summit v4.3 software.

The percentages of positive cells with the isotype controls were $<1 \%$.

\section{Determination of nitrite and arginase activity}

$\mathrm{NO}_{2}$ - accumulated in the supernatant was used as an indicator of NO production and measured using the Griess reagent as described in [28]. Culture supernatants were collected after $48 \mathrm{~h}$, and equal volumes of macrophage culture supernatants and Griess reagent (1\% sulphanilamide/ $0.1 \% \mathrm{~N}-(1$-naphthyl)ethylenediamine dihydrochloride/2.5\% $\mathrm{H}_{3} \mathrm{PO}_{4}$ ) were mixed and incubated for $10 \mathrm{~min}$ at room temperature. Absorbance was measured at $540 \mathrm{~nm}$. Nitrite concentration was determined using $\mathrm{NaNO}_{2}$ as standard.

The enzymatic activity of arginase was measured as previously described [29]. Briefly, the cell lysate was activated by heating for $10 \mathrm{~min}$ at $56^{\circ} \mathrm{C}$. L-arginine hydrolysis was conducted by incubating the activated lysate with $0.5 \mathrm{M} \mathrm{L}$-arginine ( $\mathrm{pH} 9.7$ ) at $37^{\circ} \mathrm{C}$ for 15 to 120 minutes. The reaction was stopped with $\mathrm{H}_{2} \mathrm{SO}_{4}(96 \%) / \mathrm{H}_{3} \mathrm{PO}_{4}(85 \%) /$ $\mathrm{H}_{2} \mathrm{O}$ (1:3:7, v/v/v, VWR). $\alpha$-isonitrosopropiophenone (ISPF, dissolved in $100 \%$ ethanol, Sigma) was added and incubated for $45 \mathrm{~min}$ at $100^{\circ} \mathrm{C}$, followed by $30 \mathrm{~min}$ at $4^{\circ} \mathrm{C}$. A standard curve was obtained by treating serially diluted urea with ISPF and incubated in the final step. The optical density (OD) was measured at $550 \mathrm{~nm}$.
Protein concentration of samples was measured using the BCA Protein Assay kit (Pierce) as previously described [29]. One unit of enzyme activity is defined as the amount of enzyme that catalyzes the formation of $1 \mu \mathrm{mol}$ of urea per min.

\section{Determination of L-arginine and L-ornithine concentrations}

The concentration of L-arginine and L-ornithine in plasma were measured by ion exchange chromatography and quantified by post-column ninhydrin derivatisation using an amino acid analyser (AminoTac JLC- 500/V) as described previously [30].

\section{Infection of mice and macrophages with Leishmania infantum \\ Mice}

Leishmania (L) infantum amastigotes (MHOM/MA/67/ ITMPA263 (MON-1) were derived from infected RAG1. B6 mice. BALB/c mice were infected 7 days after start of the experiment with $3 \times 10^{6}$ amastigotes in the lateral tail vein and were culled 9 days later. Spleen cells were isolated as described above and $5 \times 10^{6}$ cells were resuspended in $1 \mathrm{ml} \mathrm{M} 199$ containing $50 \mathrm{IU} / \mathrm{ml}$ penicillin, $50 \mu \mathrm{g} / \mathrm{ml}$ streptomycin, and $292 \mu \mathrm{g} / \mathrm{ml} \mathrm{L}$-glutamine (Sigma), $2 \%$ hepes and $4 \mu \mathrm{M}$ sodium bicarbonate (Sigma) and $10 \%$ fetal bovine serum (Gibco) and incubated in a humid atmosphere at $26^{\circ} \mathrm{C}$ and $5 \% \mathrm{CO}_{2}$. Eight days later, the wells were resuspended carefully and the transformed promastigotes were fixed with PBS containing $2 \%$ formaldehyde and counted using a haemocytometer.

\section{Macrophages}

$5 \times 10^{5} \mathrm{BMM} \Phi / \mathrm{ml}$ cells were plated and stimulated with $20 \mathrm{U} / \mathrm{ml} \mathrm{IL}-4$ or with $100 \mathrm{U} / \mathrm{ml} \mathrm{IFN}-\gamma$ and $500 \mathrm{U} / \mathrm{ml}$ TNF- $\alpha$ (Peprotech). Unstimulated macrophages were used as control. Four hours later, the cultures were infected with $25 \times 10^{5} / \mathrm{ml} L$. infantum promastigotes. After $96 \mathrm{~h}$, the macrophages were washed and lysed with HEPES-buffered medium containing $0.008 \%$ SDS [31] and $1 \mathrm{ml}$ of complete M199 was added to each well, incubated and the transformed promastigotes were counted as described above.

\section{Statistical analyses}

Data were evaluated for statistical differences using a two-tailed Mann-Whitney test (GraphPad Prism 5) and differences were considered statistically significant at $p<0.05$. Results are expressed as mean with $95 \%$ CI.

\section{Results}

Impact of protein energy malnutrition on weight loss

We first set up a model of malnutrition in mice to test the impact of PEM, using an isocaloric diet containing $0.7 \%$ protein. As shown in Figure 1, mice fed on the low 




Figure 1 Weight loss in mice fed on a low protein diet. Groups of BALB/C $(n=5)$ mice were fed with a low protein diet (=malnourished (MN) group, $0.7 \%$ protein) or normal diet (=control group, $14.4 \%$ protein) for 16 days. Their weight was measured at regular intervals. Data show the results of one representative experiment out of five independent experiments. Results are expressed as mean with $95 \% \mathrm{Cl}$.

protein diet lost weight steadily and on day 16 , the mice had lost an average of $26.5 \%$ of their initial weight, whereas the control mice fed on a $13.8 \%$ diet gained weight. Mice fed on the low calorie diet ate $2.53 \mathrm{~g} /$ mouse/day and mice fed on a $13.8 \%$ diet ate $3.01 \mathrm{~g} /$ mouse/day.

Impact of malnutrition on the frequency of monocytes in the bone marrow and peripheral blood mononuclear cells Next we studied the impact of malnutrition on monocytes. Since Ly6C + bone marrow monocytes are released into the peripheral blood [32], we assessed their frequency in bone marrow (BM) and peripheral blood by flow cytometry. Results presented in Figure $2 \mathrm{~A}$ show a significant increase in the frequency of Ly6C ${ }^{\text {high }}$ monocytes in the $\mathrm{BM}$ isolated from malnourished $(\mathrm{MN})$ mice $(\mathrm{p}=0.0286)$. We then measured the frequency of F4/80+ monocytes in the PBMCs from both groups of mice and detected a significant increase in the frequency of F4/80+ monocytes in the MN group ( $p=0.0286$, Figure $2 \mathrm{~B})$. As previously described [33], the majority ( $>91 \%$, data not shown) of the blood monocytes express low levels of Ly6C. Interestingly, the frequency of inflammatory F4/80 + Ly6C + cells was significantly higher in the blood of MN mice ( $p=0.0286$, Figure 2C).

These results show that in $\mathrm{MN}$ mice, the frequencies of Ly6C + monocytes and F4/80+ monocytes are increased in $\mathrm{BM}$ and PBMCs, respectively.

\section{Impact of malnutrition on macrophage effector functions in vitro}

Next we differentiated bone marrow cells from both groups of mice into mature BMM $\Phi$ and assessed their effector functions. Following 8 days of differentiation in conditioning medium, the number of F4/80+ cells was similar in both groups ( $p=0.4857$, data not illustrated). We measured the capacity of these cells to phagocytose BioParticles and the results in Figure 3A show that BMMФ derived from control and MN mice have a similar capacity to phagocytose, as the MFIs of the internalised fluorescent particles were comparable ( $p=0.4857)$. We then compared the capacity of ВМMФ derived from control and $\mathrm{MN}$ mice to produce nitric oxide (NO) and upregulate arginase. As shown in Figure 3B, BMMФ from both groups of mice produce similar levels of NO when stimulated with IFN- $\gamma$ and TNF- $\alpha(p=0.2000)$ or with LPS $(p=0.8939)$. Unstimulated BMMФ and BMMФ stimulated with IL-4 did not produce detectable levels of NO (Figure 3B). Next, we measured the capacity of ВМMФ to upregulate arginase; results presented in Figure $3 \mathrm{C}$ show that in response to IL-4, ВMMФ derived from $\mathrm{MN}$ mice express significantly increased arginase activity $(p=0.0286)$. Similarly, following stimulation with LPS, arginase activity was significantly higher in BMMФ derived from $\mathrm{MN}$ mice ( $p=0.0286$, Figure $3 C)$. The capacity of bone marrowderived neutrophils to upregulate arginase in response to IL-4 was similar in both groups (26.3 vs $28.53 \mathrm{mU} / \mathrm{mg}$ protein, $p=0.4857$ ).

These results show that whereas the production of $\mathrm{NO}$ is similar in both groups of mice, activation of BMMФ derived from MN mice with IL-4 or LPS results in increased arginase activity.

\section{Impact of malnutrition on macrophage effector functions in vivo}

The results presented in Figure $3 \mathrm{C}$ show that BMMФ from $\mathrm{MN}$ mice have the capacity to express higher arginase activity than those from control mice. To determine whether arginase was also increased in vivo in mice fed on a low protein diet, we measured the levels of arginase activity in PBMCs. As shown in Figure 4A, the levels of arginase activity were significantly higher in PBMCs from malnourished mice $(p=0.0298)$. Next the phenotype of arginase + cells was identified by flow cytometry. As shown in Figures 4B, the large majority of arginase- 1 positive cells are F4/80+ in the PBMCs, and we have previously showed that arginase 1 , but not arginase 2, is upregulated in F4/80+ cells [26]. These cells were Ly6G negative, therefore excluding neutrophils (data not shown), In the PBMCs from MN mice, the percentage of F4/80 + arginase + cells ( $p=0.0286$, Figure 4C) and the MFI of arginase ( $p=0.0421$, Figure 4D) were also significantly increased as compared to controls. Next, we determined whether increased levels of arginase activity in the PBMCs coincide with lower levels of L-arginine [30]: our results show that the levels of L-arginine are significantly lower in the plasma of $\mathrm{MN}$ mice $(65.5 \mu \mathrm{M}$ 




Figure 2 Percentages of monocytes in the bone marrow and peripheral blood mononuclear cells. The percentages of Ly6C + cells in BM (A), F4/80+ (B) and F4/80 + Ly6C + cells (C) in the PBMCs were determined by flow cytometry in cells isolated from mice fed on a low protein $(\mathrm{MN}, \mathrm{n}=4)$ or normal (control, $\mathrm{n}=4)$ diet for 16 days. Data show the results of one representative experiment out of three independent experiments. *: $p<0.05$. Results are expressed as mean with $95 \% \mathrm{Cl}$.

vs controls: $160.3 \mu \mathrm{M}, p=0.0286$, data not illustrated). In agreement with these results, the levels of L-ornithine, one of the products of arginase-mediated L-arginine catabolism, were increased (MN: 121.3 vs controls: 89.5, $p=0.0286$, data not illustrated).

Arginase activity was also significantly higher in the bone marrow ( $p=0.0286$, Figure 4E), but the phenotype of arginase + cells was not identified because the frequencies of arginase + cells were too low.

\section{Impact of malnutrition on disease development in Leishmania infantum-infected mice}

We have previously showed that increased arginase correlates with increased parasite replication and that competitive inhibition of arginase resulted in reduced parasite growth $[26,30]$. Here we determined whether the increased arginase activities observed in mice fed with a low protein diet did coincide with increased parasite load. Seven days after the start of the diets, mice were infected i.v. with Leishmania $(L)$. infantum and 8 days later, parasite load and arginase activities were measured in the spleen. As shown in Figure $5 \mathrm{~A}$, the increased parasite load in the spleen of MN mice $(p=0.0286)$ coincided with increased arginase activity ( $p=0.0286$, Figure $5 \mathrm{~B}$ ).

In macrophages, efficient parasite replication is controlled at least in part by arginase: catabolism of L-arginine by arginase results in the production of polyamines that the parasites use for their replication; competitive inhibition of arginase reduced the production of polyamines in BMMФ activated with IL-4 and thereby clearly reduced parasite replication [26]. Since BMMФ derived from $M N$ mice express more arginase, we assessed whether this provides a more permissive environment for parasite growth; we activated BMMФ with IL-4 and infected them with L. infantum and measured their growth as well as arginase activity; unstimulated macrophages as well as macrophages stimulated with IFN- $\gamma$ and TNF- $\alpha$ were used as controls. As shown in Figure 5C, L. infantum grew significantly better in IL-4-stimulated BMM $\Phi$ derived from MN mice $(p=0.0286)$, and this increase in parasite burden coincided with increased arginase activity $(p=0.0286$, Figure 5D). As shown previously [26], no parasites could be detected in BMMФ activated with IFN- $\gamma$ and TNF- $\alpha$; no significant difference was observed in parasite growth in unstimulated $В M M \Phi$ derived from $\mathrm{MN}$ and control mice ( $p=0.6857$, Figure $5 \mathrm{C}$ ).

The results presented in Figure 5 show that L. infantum-infected mice on a low protein diet have a significantly higher parasite burden paralleled by significantly increased arginase activity, which provides a more permissive environment in host macrophages for parasite growth. 

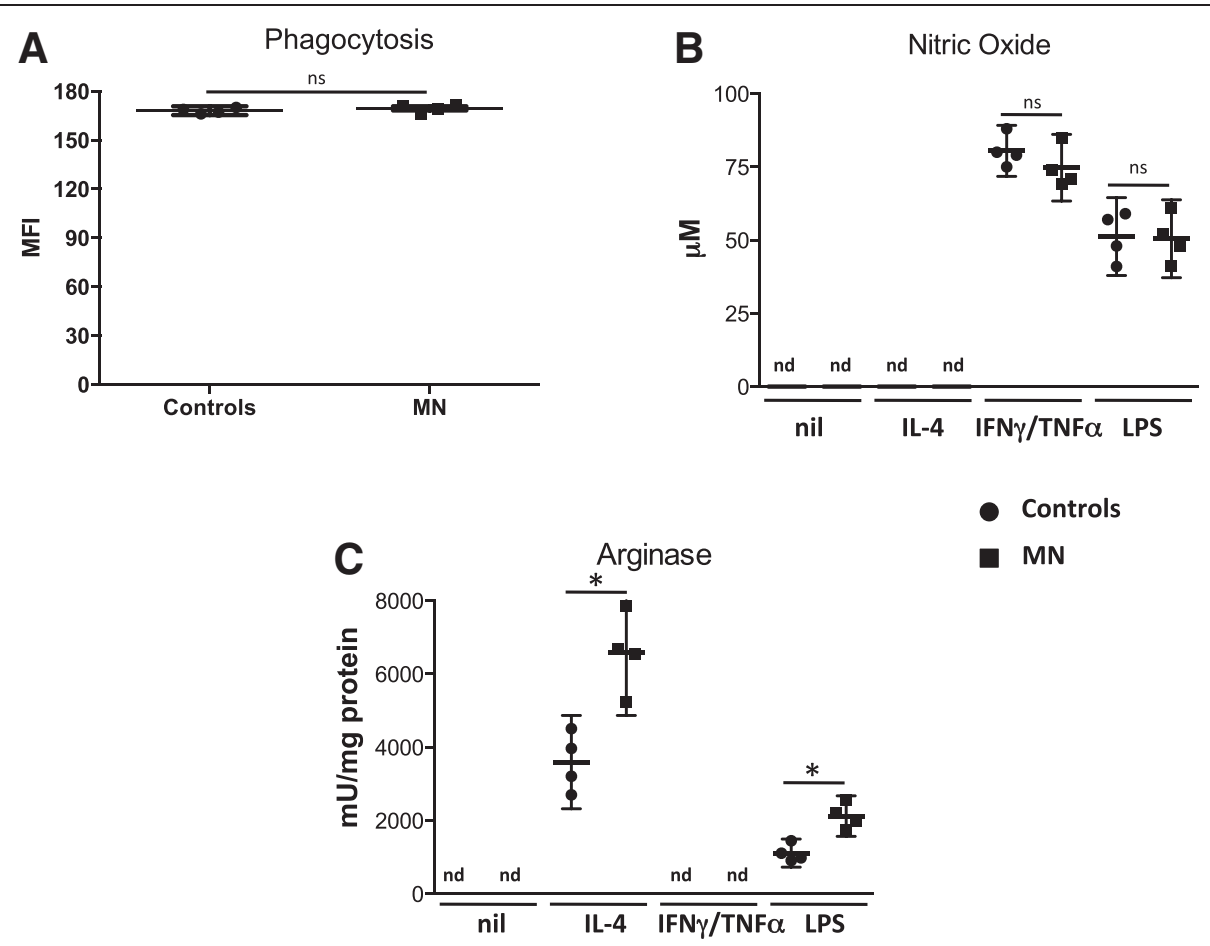

- Controls

- MN

Figure 3 Bone marrow derived macrophage effector functions. Bone marrow cells were isolated from the bone marrow from mice fed on a low protein $(M N, n=4)$ or normal (control, $n=4$ ) diet for 16 day and were differentiated in conditioning medium. Eight days later, the capacity of these cells to phagocytose particles was determined by flow cytometry (A). In addition, BMMФ were activated with IL-4, IFN- $\gamma$ and TNF-a, LPS or left unactivated (nil) and the production of nitric oxide (B) and the activity of arginase (C) were measured as described in material and methods. Data show the results of one representative experiment out of four independent experiments. ${ }^{*}: p<0.05$. Box $=$ interquartile range and median; whiskers $=$ range. nd $=$ not detectable.

\section{Discussion}

PEM is one of the major causes of immunosuppression, modifying both innate and adaptive immunity. It is highly prevalent in low-income countries, particularly in children [4]. In the developed world, PEM is also a serious health concern, mainly seen in the elderly, with up to $10 \%$ of older people undernourished in nursing homes and up to $50 \%$ of older people undernourished when discharged from hospital [34]. Malnutrition is associated with a plethora of problems, such as fatigue, anaemia, cognitive abnormalities, immune dysfunctions and increased susceptibility to infections [34]. Monocytes and macrophages play a major role in the elimination of pathogens. Here we show that the frequency of monocytes is increased in the bone marrow and PBMCs of MN mice, suggesting a dysregulation in the haematopoiesis in these mice. This is in agreement with a study by Borelli et al. [35] that showed a 2.5-fold increase in the number of peripheral blood monocytes. Whereas macrophages and monocytes can be instructed to kill intracellular pathogens, they can also act as "safe target". Indeed, in Leishmania major infected nonhealing mice, macrophage-granulocytes precursor cells were shown to be dramatically increased during infection, thereby offering a large number of host cells for the parasites to infect [36,37]. Since these cells have not yet developed their full microbicidal potential [37], the parasites cannot be killed efficiently and the myeloid cells represent therefore a more permissive environment for the parasites to survive. We also showed an increase in the frequency of F4/80 + Ly6C + inflammatory macrophages in the blood of $\mathrm{MN}$ mice; these macrophages have been shown to be rapidly recruited to sites of inflammation. Since malnutrition has been associated with chronic inflammation [38], this might explain the increased frequency of these macrophages during PEM.

Whereas we detected arginase activity in the BM cells, we were not able to able to identify the phenotype of arginase-expressing cells. Since other cells than macrophages have been shown to express arginase, it is possible that cells such as dendritic cells, neutrophils $[27,28]$ or innate lymphoid cells [39] might contribute.

Here, we showed that PEM did not impact on the capacity of $B M M \Phi$ to produce $\mathrm{NO}$ in response to activation with IFN- $\gamma$ and TNF- $\alpha$ or LPS; nor on the capacity of ВММФ capacity to kill intracellular Leishmania parasites. We also showed that in vitro, bone marrow cells from malnourished mice did proliferate and differentiate similarly to those from control mice as both the number 


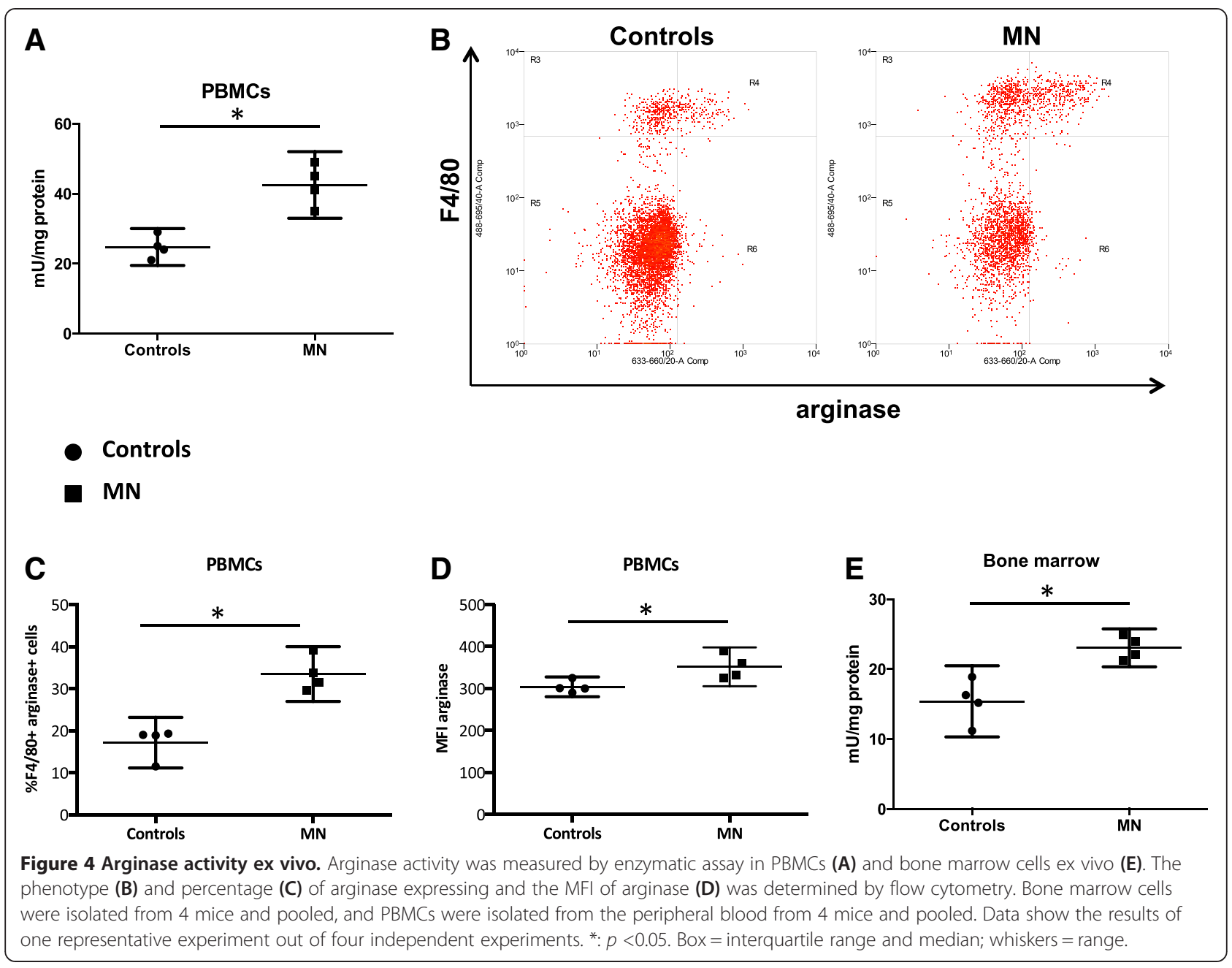

of cells after 8 days of differentiation were similar. Furthermore, phagocytosis of bioparticles was not impaired in $В M M \Phi$ derived from malnourished mice. In contrast, it has been previously shown that some macrophage functions are altered during PEM: the phagocytic capacity and production of superoxide anions, indicative of their microbicidal competence, were shown to be impaired [10,40,41], suggesting that increased susceptibility to disease might be due to an impaired capacity of phagocytic cells to kill pathogens. The discrepancies between these studies and ours could be due to the different macrophages used: ВMMФ in our study versus elicited peritoneal exudate macrophages in the other studies [10,40,41]. Macrophages derived from different compartments such as bone marrow, spleen or peritoneum have different capacities to phagocytose dextran beads [42]. It is also possible that the different diets used, characterised by differences in calories, fat, micronutrient and protein contents, also impact on macrophage effector functions.

We have previously shown that bone marrow derived macrophages from younger mice express significantly higher levels of arginase 1 than aged mice and promote parasite growth more efficiently [43]. Furthermore, $L$. major-infected younger mice develop exacerbated lesion pathology and higher parasite burdens than aged mice [43]. A previous study from 1984 showed that arginase was decreased in the saliva of children with different grades of PEM [44]. We have previously compared the levels of arginase activity in the saliva of severely malnourished patients with visceral leishmaniasis and severely malnourished patients with visceral leishmaniasis and HIV co-infection and did not find significant differences or correlation between the levels of malnutrition and the levels of arginase activity [21]; nor did we find differences when compared to healthy controls (P. Kropf, unpublished data).

Our results show that ВМMФ derived from malnourished mice express significantly more arginase in response to IL-4 or LPS, and we also measured considerably more arginase activity in the bone marrow cells and PBMCs of malnourished mice directly ex vivo. We and others have shown that increased arginase activity is associated with the severity of a variety of infectious diseases $[20,21,23,45,46]$. 




At least two distinct arginase-mediated mechanisms can impact on the severity of disease:

i) Increased catabolism of L-arginine by arginase results in the depletion of L-arginine from the microenvironment; since $\mathrm{L}$-arginine is essential for efficient $\mathrm{T}$ cell activation, this decrease in $\mathrm{L}$-arginine results in impaired $\mathrm{T}$ cell responses $[17,18,47,48]$. In an experimental model of leishmaniasis, we have recently shown that increased arginase activity causes local depletion of L-arginine, which impairs the capacity of $\mathrm{T}$ cells in the lesion to proliferate and to produce interferon- $\gamma$ [30]. Healing, induced by chemotherapy, resulted in control of arginase activity and reversal of local immunosuppression; competitive inhibition of arginase as well as supplementation with L-arginine restored $\mathrm{T}$ cell effector functions and reduced pathology and parasite growth at the site of lesions [30]. Indeed, our results also show that the levels of Larginine are lower in $\mathrm{MN}$ mice. L-arginine is derived from 1) turnover of cellular protein; 2) from endogenous synthesis: by de novo synthesis from citrulline; and 3) the diet via protein, which contained from $3-15 \%$ of L-arginine $[14,15]$. It is therefore likely that insufficient level of protein in the diet result in reduced levels of L-arginine in plasma [49-51]. Consequently, both PEM and increased levels of arginase might contribute to the lower level of L-arginine.

PEM malnutrition not only results in lower levels of L-arginine, it also results in severe alteration of the levels of different amino acid [49-51]. It is likely that these changes impact on macrophage effector functions; for example, glutamine deprivation impacts on antigen presentation, HLA-DR expression and cytotoxic effect of TNF- $\alpha$ of macrophages [52]. Furthermore, increased intracellular levels of arginase-induced L-arginine catabolites such as ornithine, putrescine, spermine and spermidine can downregulate macrophage [53-55]. Of note, we have previously shown that in vitro, L-arginine deprivation did not impact on arginase activity and NO production [56]. 
ii) Increased arginase activity has also been shown to promote the growth of Leishmania parasites directly via the polyamine synthesis in macrophages [26]: arginase hydrolyses L-arginine to urea and ornithine; the latter is the main intracellular source for the synthesis of polyamines, which are necessary for parasite growth. Inhibition of arginase in activated ВМMФ clearly reduced parasite replication [26]. Indeed, our results show that BMMФ derived from MN mice express significantly more arginase and provide a more permissive environment for Leishmania replication. Furthermore, the increased parasite burden in the spleen of MN BALB/c mice infected with $L$. infantum coincides with increased arginase activity.

To the best of our knowledge, this is the first study that shows that PEM results in increased arginase activity in monocytes and macrophages, however the mechanisms responsible for this upregulation of arginase have not been identified yet. Upregulation of arginase has been extensively described in murine macrophages: cytokines such as IL-4 and IL-13, which can synergize with IL-10 and IL-21, as well as IL-6, induce the expression of arginase; in addition, lipospolysaccharide and lipoprotein, as well as inflammatory stimuli such as thioglycollate, carrageenan and casein can also induce arginase [13]. Therefore, it is tempting to speculate that upregulation of arginase is induced as a result of PEM-induced inflammation. Whereas arginase upregulation in macrophages during PEM is STAT6- or TLRs- dependent remains to be established [57].

\section{Conclusion}

Our results show that macrophages and monocytes from malnourished mice express significantly more arginase both in vitro and in vivo. We proposed that increased arginase-mediated L-arginine catabolism is a mechanism likely to contribute to more severe disease by promoting parasite growth. Further work into the impact of arginasemediated L-arginine catabolism during PEM is warranted as this may result in the identification of novel therapeutic dietary interventions that might interfere with this pathway and therefore improve immune responses and resistance to infectious diseases.

\section{Additional files}

Additional file 1: High protein diet.

Additional file 2: Low protein diet.

\section{Competing interests}

The authors declare that they have no competing interests.

\section{Authors' contributions}

KC, VY, CM, HE and SS performed experiments and analyzed data. SH, PB, MMo, MMu and IM analysed data. PK designed the research, performed experiments, analyzed data and wrote the manuscript. All authors read and approved the final manuscript.

\section{Acknowledgments}

This work was supported by funds received from The Wellcome Trust (089201/Z/09/Z, PK and KC). We thank Drs. F. Tacchini-Cottier and B. Griffin for helpful discussions and critical reading of the manuscript.

\section{Author details}

${ }^{1}$ Department of Medicine, Section of Immunology, Faculty of Medicine, Imperial College London, Norfolk Place, London W2 1PG, UK. ${ }^{2}$ Immunology and Infection Department, London School of Hygiene and Tropical Medicine, London, UK. ${ }^{3}$ Department of Biochemistry, WHO Immunology Research and Training Center, University of Lausanne, Lausanne, Switzerland. ${ }^{4}$ School of Biological Sciences, Royal Holloway, University of London, Egham, UK. ${ }^{5}$ International AIDS Vaccine Initiative Human Immunology Laboratory, Faculty of Medicine, Imperial College London, London, UK. ${ }^{6}$ Department of Cellular Immunology, Max-Planck-Institute for Immunobiology and Epigenetics, Freiburg, Germany. ${ }^{7}$ Third Department of Medicine (Hematology, Oncology, and Pneumology), University Medical Center Mainz, Mainz, Germany.

Received: 20 May 2014 Accepted: 24 September 2014

Published: 24 October 2014

\section{References}

1. Katona P, Katona-Apte J: The interaction between nutrition and infection. Clin Infect Dis 2008, 46:1582-1588.

2. Bhutta ZA, Salam RA: Global nutrition epidemiology and trends. Ann Nutr Metab 2012, 61(Suppl 1):19-27.

3. Beisel WR: Nutrition in pediatric HIV infection: setting the research agenda. Nutrition and immune function: overview. J Nutr 1996, 126:2611S-2615S.

4. Schaible UE, Kaufmann SH: Malnutrition and infection: complex mechanisms and global impacts. PLoS Med 2007, 4:e115.

5. Woodward B: Protein, calories, and immune defenses. Nutr Rev 1998, 56:S84-S92.

6. Chandra RK: Nutrition and immunity in the elderly. Nutr Res Rev 1991, 4:83-95

7. Najera O, Gonzalez C, Toledo G, Lopez L, Cortes E, Betancourt M, Ortiz R: CD45RA and CD45RO isoforms in infected malnourished and infected well-nourished children. Clin Exp Immunol 2001, 126:461-465.

8. Rodriguez L, Gonzalez C, Flores L, Jimenez-Zamudio L, Graniel J, Ortiz R: Assessment by flow cytometry of cytokine production in malnourished children. Clin Diagn Lab Immunol 2005, 12:502-507.

9. Redmond HP, Leon P, Lieberman MD, Hofmann K, Shou J, Reynolds JV, Goldfine J, Johnston RB Jr, Daly JM: Impaired macrophage function in severe protein-energy malnutrition. Arch Surg 1991, 126:192-196.

10. de la Fuente M, Munoz ML: Impairment of phagocytic process in macrophages from young and old mice by protein malnutrition. Ann Nutr Metab 1992, 36:41-47.

11. Schaffer MR, Tantry U, Ahrendt GM, Wasserkrug HL, Barbul A: Acute protein-calorie malnutrition impairs wound healing: a possible role of decreased wound nitric oxide synthesis. J Am Coll Surg 1997, 184:37-43.

12. Fock RA, Rogero MM, Vinolo MA, Curi R, Borges MC, Borelli P: Effects of protein-energy malnutrition on NF-kappaB signalling in murine peritoneal macrophages. Inflammation 2010, 33:101-109.

13. Munder M: Arginase: an emerging key player in the mammalian immune system. Br J Pharmacol 2009, 158:638-651.

14. Morris SM Jr: Recent advances in arginine metabolism: roles and regulation of the arginases. Br J Pharmacol 2009, 157:922-930.

15. Morris SM Jr: Arginases and arginine deficiency syndromes. Curr Opin Clin Nutr Metab Care 2012, 15:64-70.

16. Nagaraj S, Gabrilovich DI: Myeloid-derived suppressor cells in human cancer. Cancer J 2010, 16:348-353.

17. Bronte $\mathrm{V}$, Zanovello P: Regulation of immune responses by L-arginine metabolism. Nat Rev Immunol 2005, 5:641-654.

18. Ochoa AC, Zea AH, Hernandez C, Rodriguez PC: Arginase, prostaglandins, and myeloid-derived suppressor cells in renal cell carcinoma. Clin Cancer Res 2007, 13:721s-726s

19. Morris SM Jr: Recent advances in arginine metabolism. Curr Opin Clin Nutr Metab Care 2004, 7:45-51.

20. Cloke T, Garvery L, Choi BS, Abebe T, Hailu A, Hancock M, Kadolsky U, Bangham CRM, Munder M, Müller I, Taylor GP, Kropf P: Increased arginase activity correlates with disease severity in HIV seropositive patients. J Infect Dis 2010, 202:374-385. 
21. Takele Y, Abebe T, Weldegebreal T, Hailu A, Hailu W, Ali J, Diro E, Sisay Y, Cloke T, Modolell M, Munder M, Müller I, Kropf P: Arginase activity in the blood of patients with visceral leishmaniasis and HIV infection. PLOS NTD 2012, 7:e1977.

22. Abebe T, Takele T, Weldegebreal T, Cloke T, Closs E, Corset C, Hailu A, Hailu W, Sisay Y, Corware K, Modolell M, Munder M, Tacchini-Cottier F, Müller I, Kropf P: Arginase: a marker of disease status in patients with visceral leishmaniasis. PLOS NTD 2013, 7:e2134.

23. Abebe T, Hailu A, Woldeyes M, Mekonene W, Bilch K, Cloke T, Fry L, al Basatena N-K S, Corware K, Modolell M, Munder M, Tacchini-Cottier F, Müller I, Kropf P: Local increase of arginase activity in lesions of patients with cutaneous leishmaniasis in Ethiopia. PLOS NTD 2012, 6:e1684.

24. Malafaia G: Protein-energy malnutrition as a risk factor for visceral leishmaniasis: a review. Parasite Immunol 2009, 31:587-596.

25. Han JM, Levings MK: Immune regulation in obesity-associated adipose inflammation. J Immunol 2013, 191:527-532.

26. Kropf P, Fuentes JM, Fahnrich E, Arpa L, Herath S, Weber V, Soler G, Celada A, Modolell M, Muller I: Arginase and polyamine synthesis are key factors in the regulation of experimental leishmaniasis in vivo. Faseb J 2005, 19:1000-1002

27. Munder M, Mollinedo F, Calafat J, Canchado J, Gil-Lamaignere C, Fuentes JM, Luckner C, Doschko G, Soler G, Eichmann K, Müller FM, Ho AD, Goerner M, Modolell M: Arginase I is constitutively expressed in human granulocytes and participates in fungicidal activity. Blood 2005, 105:2549-2556.

28. Munder M, Eichmann K, Moran JM, Centeno F, Soler G, Modolell M: Th1/Th2-regulated expression of arginase isoforms in murine macrophages and dendritic cells. J Immunol 1999, 163:3771-3777.

29. Kropf P, Baud D, Marshall SE, Munder M, Mosley A, Fuentes JM, Bangham CR, Taylor GP, Herath S, Choi BS, Soler G, Teoh T, Modolell M, Muller I: Arginase activity mediates reversible $\mathrm{T}$ cell hyporesponsiveness in human pregnancy. Eur J Immunol 2007, 37:935-945

30. Modolell M, Choi B-S, Ryan RO, Hancock M, Titus RG, Abebe T, Hailu A, Müller I, Rogers M, Bangham CRB, Munder M, Kropf P: Local suppression of $T$ cell responses by arginase-induced L-arginine depletion in nonhealing leishmaniasis. PLOS Negl Trop Dis 2009, 14:e480.

31. Kropf P, Brunson K, Etges R, Müller I: The Leishmaniasis Model. In Immunology of Infection. Volume 25. 1st edition. San Diego: Academic; 1998:419-458 [Kaufmann SHE, Kabelitz D (Series Editor): Methods in Microbiology].

32. Gordon S, Taylor PR: Monocyte and macrophage heterogeneity. Nat Rev Immunol 2005, 5:953-964.

33. Shi C, Pamer EG: Monocyte recruitment during infection and inflammation. Nat Rev Immunol 2011, 11:762-774.

34. Morley JE: Undernutrition in older adults. Fam Pract 2012, 29(Suppl 1):i89-i93.

35. Borelli P, Barros FE, Nakajima K, Blatt SL, Beutler B, Pereira J, Tsujita M, Favero GM, Fock RA: Protein-energy malnutrition halts hemopoietic progenitor cells in the G0/G1 cell cycle stage, thereby altering cell production rates. Braz J Med Biol Res 2009, 42:523-530.

36. Mirkovich AM, Galelli A, Allison AC, Modabber FZ: Increased myelopoiesis during Leishmania major infection in mice: generation of 'safe targets', a possible way to evade the effector immune mechanism. Clin Exp Immunol 1986, 64:1-7.

37. Hoover DL, Nacy CA: Macrophage activation to kill Leishmania tropica: defective intracellular killing of amastigotes by macrophages elicited with sterile inflammatory agents. J Immunol 1984, 132:1487-1493.

38. Hashimoto T, Perlot T, Rehman A, Trichereau J, Ishiguro H, Paolino M, Sigl V, Hanada T, Hanada R, Lipinski S, Wild B, Camargo SM, Singer D, Richter A, Kuba K, Fukamizu A, Schreiber S, Clevers H, Verrey F, Rosenstiel P, Penninger JM: ACE2 links amino acid malnutrition to microbial ecology and intestinal inflammation. Nature 2012, 487:477-481.

39. Bando JK, Nussbaum JC, Liang HE, Locksley RM: Type 2 innate lymphoid cells constitutively express arginase-I in the naive and inflamed lung. J Leukoc Biol 2013, 94:877-884.

40. Teshima S, Rokutan K, Takahashi M, Nikawa T, Kido Y, Kishi K: Alteration of the respiratory burst and phagocytosis of macrophages under protein malnutrition. J Nutr Sci Vitaminol (Tokyo) 1995, 41:127-137.

41. Redmond HP, Shou J, Kelly CJ, Leon P, Daly JM: Protein-calorie malnutrition impairs host defense against Candida albicans. J Surg Res 1991, 50:552-559.

42. Wang C, Yu X, Cao Q, Wang Y, Zheng G, Tan TK, Zhao H, Zhao Y, Harris D: Characterization of murine macrophages from bone marrow, spleen and peritoneum. BMC Immunol 2013, 14:6
43. Muller I, Hailu A, Choi BS, Abebe T, Fuentes JM, Munder M, Modolell M, Kropf P: Age-related alteration of arginase activity impacts on severity of leishmaniasis. PLoS Negl Trop Dis 2008, 2:e235

44. Agarwal PK, Agarwal KN, Agarwal DK: Biochemical changes in saliva of malnourished children. Am J Clin Nutr 1984, 39:181-184.

45. Cloke T, Munder M, Bergin P, Herath S, Modolell M, Taylor GP, Müller Kropf P: Phenotypic alteration of neutrophils in the blood of HIV seropositive patients. PLoS One 2013, 8:e72034.

46. Zea AH, Culotta KS, Ali J, Mason C, Park HJ, Zabaleta J, Garcia LF, Ochoa AC: Decreased expression of CD3 zeta and nuclear transcription factor kappa B in patients with pulmonary tuberculosis: potential mechanisms and reversibility with treatment. J Infect Dis 2006, 194:1385-1393.

47. Popovic PJ, Zeh HJ 3rd, Ochoa JB: Arginine and immunity. J Nutr 2007, 137:1681S-1686S.

48. Munder M, Choi B-S, Rogers M, Kropf P: L-arginine deprivation impairs Leishmania major-specific T cell responses. Eur J Immunol 2009, 39:2161-2172

49. Padilla H, Sanchez A, Powell RN, Umezawa C, Swendseid ME, Prado PM, Sigala R: Plasma amino acids in children from Guadalajara with kwashiorkor. Am J Clin Nutr 1971, 24:353-357.

50. Poeze M, Bruins MJ, Luiking YC, Deutz NE: Reduced caloric intake during endotoxemia reduces arginine availability and metabolism. Am J Clin Nutr 2010, 91:992-1001.

51. Moyano D, Vilaseca MA, Artuch R, Lambruschini N: Plasma amino acids in anorexia nervosa. Eur J Clin Nutr 1998, 52:684-689.

52. Roth E: Immune and cell modulation by amino acids. Clin Nutr 2007, 26:535-544.

53. Hasko G, Kuhel DG, Marton A, Nemeth ZH, Deitch EA, Szabo C: Spermine differentially regulates the production of interleukin-12 p40 and interleukin-10 and suppresses the release of the Thelper 1 cytokine interferon-gamma. Shock 2000, 14:144-149.

54. Perez-Cano FJ, Franch A, Castellote C, Castell M: Immunomodulatory action of spermine and spermidine on NR8383 macrophage line in various culture conditions. Cell Immunol 2003, 226:86-94.

55. Zhang M, Caragine T, Wang H, Cohen PS, Botchkina G, Soda K, Bianchi M, Ulrich P, Cerami A, Sherry B, Tracey KJ: Spermine inhibits proinflammatory cytokine synthesis in human mononuclear cells: A counterregulatory mechanism that restrains the immune response. J Exp Med 1997, 185:1759-1768.

56. Choi BS, Martinez-Falero IC, Corset C, Munder M, Modolell M, Muller I, Kropf P: Differential impact of L-arginine deprivation on the activation and effector functions of T cells and macrophages. J Leukoc Biol 2009, 85:268-277

57. El Kasmi KC, Qualls JE, Pesce JT, Smith AM, Thompson RW, Henao-Tamayo M Basaraba RJ, Konig T, Schleicher U, Koo MS, Kaplan G, Fitzgerald KA, Tuomanen El, Orme IM, Kanneganti TD, Bogdan C, Wynn TA, Murray PJ: Toll-like receptor-induced arginase 1 in macrophages thwarts effective immunity against intracellular pathogens. Nat Immunol 2008, 9:1399-1406.

doi:10.1186/1743-7075-11-51

Cite this article as: Corware et al:: Protein energy malnutrition increases arginase activity in monocytes and macrophages. Nutrition \& Metabolism 2014 11:51

\section{Submit your next manuscript to BioMed Central and take full advantage of:}

- Convenient online submission

- Thorough peer review

- No space constraints or color figure charges

- Immediate publication on acceptance

- Inclusion in PubMed, CAS, Scopus and Google Scholar

- Research which is freely available for redistribution 